\title{
La denuncia al eurocentrismo en el pensamiento social latinoamericano y la problemática de la universalidad del conocimiento
}

\author{
Sergio Caba \\ Universidad Nacional de Cuyo \\ Email: sergioeduardo.caba@gmail.com \\ Gonzalo García \\ Email: elektropura@gmail.com
}

Centro de Estudios Latinoamericanos, Universidad Nacional de San Martín

\begin{abstract}
Resumen: Desde la sociología, el interés en la dimensión conceptual del pensamiento social latinoamericano ha debido enfrentar la crítica de una deficiencia teórica en torno a las capacidades que define el status científico de la disciplina: la descripción de un objeto de conocimiento postulado como universal. Para dar una idea de cómo se enmarca esta crítica, nos apoyamos en este ensayo en la lectura de Chernilo y Mascareño que habilita el tratamiento inicial de la problemática. Luego, pasamos también revista a la decolonialidad en clave de las nuevas respuestas que desde el pensamiento social latinoamericano permiten reformular, ya de manera radical, la crítica a las pretensiones de universalidad del conocimiento. Por último, proponemos destacar la distinción entre teoría social y teoría sociológica para finalizar con una interrogante que deja abierta la discusión.
\end{abstract}

Palabras clave: pensamiento social latinoamericano, obstáculos epistemológicos, universalidad, decolonialidad.

\section{The denouncement of eurocentrism in Latin American social thought and the problematic of the universality of knowledge}

\begin{abstract}
From sociology, the interest in the conceptual dimension of Latin American social thought has been criticized of having a theoretical deficiency en regards the capacities that the scientific status of the discipline defines: the description of an object of knowledge postulated as universal. To give an idea of how this critic is framed, on this essay we rest on the readings of Daniel Chernilo and Aldo Mascareño (2005) that enables the initial treatment of the problem. We then focus on decolonial thought rescuing its radical critic to the claims of universality of reason. In efforts to propose an opened discussion, we finally introduce the distinction between social theory and sociological theory to end with a query that leaves the discussion open.
\end{abstract}

Key words: Latin American social thought, epistemological obstacles, universality, decoloniality. 


\title{
A denuncia do eurocentrismo no pensamento social latino- americano e o problema da universalidade do conhecimento
}

\begin{abstract}
Resumo: Desde a sociologia, o interesse na dimensão conceitual do pensamento social latino-americano tem enfrentado a crítica de uma deficiência teórica em torno das capacidades que definem o status científico da disciplina: a descrição de um objeto de conhecimento postulado como universal. Para dar uma ideia de como é enquadrada esta crítica, apoiamo-nos neste ensaio na leitura de Chernilo e Mascareño que permite o tratamento inicial do problema. Então também nós revemos o conceito de descolonialidade em chave das novas respostas que a partir do pensamento social latino-americano permitem a reformulação, de maneira radical, a crítica às pretensões de universalidade do conhecimento. Finalmente, propõe-se a enfatizar a distinção entre teoria social e teoria sociológica para terminar com uma pergunta que deixa em aberto a discussão.
\end{abstract}

Palavras-chave: pensamento social latino-americano, obstáculos epistemológicos, universalidade, descolonialidade.

$* * *$

\section{Introducción $^{1}$}

El pensamiento latinoamericano, en tanto corriente intelectual abocada a tematizar la realidad social continental, constituye el objeto central de este ensayo. Conscientes de las resistencias que implica asumir esta categoría, en cuanto se insiste en comparar la producción intelectual regional con un canon elaborado en otros contextos, desconociendo así el camino que filosóficamente se ha recorrido en América Latina para abordar la cuestión de un pensamiento “propio”, destacamos en primer lugar los aportes del historicismo filosófico mexicano que delimita la unidad del discurso intelectual en torno al predominio de una lengua común -el español-y su persistente atención a problemas históricos y culturales (Gaos 1993). El pensamiento latinoamericano se refiere, en esta perspectiva, a un discurso integrador, orientado a la generación de utopías y objetos inmanentes, por sobre el interés racionalizador. Se trata de una tradición que no está sujeta a los requisitos y procedimientos estrictos de enfoques filosóficos, ni de las disciplinas de las ciencias sociales. Más bien, comprende la articulación de diversas formas de expresión -poemas, artículos periodísticos, ensayos literarios, filosóficos o sociológicos-y conocimiento con énfasis en dimensiones políticas, pedagógicas y estéticas.

En la filiación de esta tradición, Germani (2010) planteó la necesidad de una sociología fundada en la ruptura con el pasado intelectual latinoamericano. En efecto, propone una sociología científica capaz de comprobar sus afirmaciones a través de procedimientos empíricos y objetos teóricos generalizables; una sociología que se renueve y exponga permanentemente al examen de la ciencia, superando el ensayismo y la especulación filosófica ${ }^{2}$. No obstante, a mediados de 1960 y en la década posterior, la apuesta de Germani enfrentó el duro diagnóstico del marxismo y del depedentismo $^{3}$, cuestionando el enfoque estructural-funcionalista y sus 
ribetes desarrollistas bajo la premisa de un compromiso intelectual con los problemas históricos de la realidad social continental -el subdesarrollo, la dependencia, el imperialismo. Pero esta sociología comprometida que se verá realizada en la teoría de la dependencia y la teología de la liberación no parece suficiente: en clave decolonial, el marxismo no puede superar por sí mismo las limitaciones de su eurocentrismo; no deja de ser una perspectiva crítica dentro de la misma racionalidad eurocéntrica.

En torno a estas consideraciones, el propósito de este ensayo es presentar y discutir dos lecturas: primero, la interpretación de los obstáculos epistemológicos del pensamiento social/sociológico latinoamericano que impedirían construir elaboraciones teóricas con pretensiones universalistas; segundo, las propuestas decoloniales desprendidas de algunas de las tesis centrales del proyecto latinoamericano Modernidad/ Colonialidad, que argumentan la necesidad de rehuir de toda forma de universalismo. Veremos que este debate alude principalmente a la problemática filosófica de las condiciones epistemológica acerca de las pretensiones. A partir de las reflexiones de Chernilo y Mascareño (2005), esto se identifica como la debilidad teórica de la tradición intelectual; en cuanto a la posición decolonial, se sostiene un aspecto aún más radical que implica un rechazo a la universalidad en tanto crítica al eurocentrismo como designio global

Chernilo y Mascareño son dos sociólogos chilenos vinculados por una línea de investigación teórica, con énfasis en problemáticas y autores contemporáneos de la sociología. Su reflexión nos permite representar una posición crítica clásica hacia el pensamiento social latinoamericano, acerca de sus condiciones para adecuarse a un canon disciplinario. En la filosofía, por ejemplo, existe un extenso debate acerca de la posibilidad de que lo producido en América Latina tenga su propio derecho a ser llamado como tal. Pero ello implicó una revisión de la definición misma de lo que entendemos por filosofía. Para la sociología, disciplina heredera de la Ilustración y que nace para conceptualizar las transformaciones sociales de la modernidad, ocurre algo similar: la autocomprensión de su cientificidad radica fundamentalmente en la pretensión universalista -desde lo conceptual, metodológico y normativo-del conocimiento sociológico (Chernilo 2011). La lectura se dirige entonces hacia el examen de la propia tradición: ¿en qué condiciones se encuentra la producción intelectual latinoamericana en relación a este requisito?

En la perspectiva decolonial, la lectura es radicalmente distinta, se reorienta al eurocentrismo visto como dimensión epistémica homogenizante y la respuesta no puede ser de otra forma que en la recuperación de aquello que escapa a la racionalidad moderna. Se acuña entonces el concepto de descolonización epistemológica y la necesidad de rehuir a toda forma de eurocentrismo/universalismo para avanzar hacia un pensamiento social/ crítico latinoamericano. Dentro de esta trayectoria teórica, un denominativo común se puede hallar en la literatura conocida bajo la etiqueta de postcolonialismo latinoamericano, o en el nombre del grupo Modernidad/ Colonialidad, cuyos principales referentes son Enrique Dussel, Walter 
Mignolo, Santiago Castro-Gómez, Arturo Escobar, Ramón Grosfoguel, Aníbal Quijano, Edgardo Lander, entre otros ${ }^{4}$. Nos referiremos a esta constelación y a sus aportes como decolonial(es).

Para dar cuenta de lo anterior, presentamos en un primer apartado la crítica de los obstáculos epistemológicos que introduce la problemática de la universalidad del conocimiento. Luego, exponemos la crítica decolonial en base a ciertos puntos de argumentación centrales como rechazo de la problemática. En el tercer apartado enfocamos la discusión en la distinción entre teoría social y teoría sociológica. A modo de cierre, anticipamos que bajo dicha distinción, ambas lecturas deben ser revisitadas, considerando que la problemática señalada no puede quedar resuelta en una tipificación del conocimiento sociológico que de paso descaracteriza la tradición del pensamiento latinoamericano, pero tampoco en una renuncia a la conversación.

\section{Obstáculos epistemológicos}

Desde la sociología, se identifica en el trabajo de Chernilo y Mascareño (2005) tres obstáculos epistemológicos ${ }^{5}$ que caracterizarían las dificultades del pensamiento social latinoamericano para adecuarse al canon de la disciplina. Se argumenta que:

La relativa debilidad teórica de la sociología latinoamericana le ha obligado a confrontar el carácter universalista que es propio del canon sociológico. A su vez, sin embargo, parte de ella (buena parte) no ha logrado superar una visión particularista y ha entendido la modernidad latinoamericana como versión incompleta de la europea o ha reflexionado sobre el ethos identitario propio, poniéndose al servicio de los actores (Chernilo y Mascareño 2005: 19).

Lo propio del canon está dado por la pretensión de universalidad del conocimiento sociológico, cuyos obstáculos para desarrollar una formulación teórica de tales características, además de las respectivas respuestas de su superación, serían tres:

a) Un obstáculo estructural que se superaría con la tesis de la diferenciación funcional concéntrica: pensar que la modernidad latinoamericana es una versión limitada de la modernidad europea -o de la derivada norteamericana- y, por tanto, ésta señala el camino futuro de aquella o su punto de fuga.

b) Un obstáculo normativo que se superaría con la tesis del cosmopolitismo en tanto trasfondo normativo de integración de la sociedad mundial: pensar que la sociedad, como objeto de la sociología latinoamericana, adquiere la forma de la unidad territorial del Estadonación o de comunidades éticas de carácter particularista. 
c) La falta de autonomía que se superaría mediante la cualidad de la sociedad como orden emergente que no se deja instrumentalizar por los actores: el conocimiento sociológico es un instrumento al servicio de la modelación política de la sociedad, y consecuentemente debe transformarse en programa de acción para ser aplicable al contexto latinoamericano.

Los autores afirman que la relativa debilidad teórica del pensamiento social latinoamericano se manifiesta en forma de una relativa incapacidad para responder al desafío teórico-empírico de trabajar con una idea de Sociedad que fundamente su cientificidad, adoptando un punto de vista lo suficientemente abstracto para capturar particularidades como parte de una-sola-sociedad. Es decir, más allá de las diferencias contextuales, se trata de un objeto que no se agota en un determinado contexto histórico, cultural y geográfico. Ante este desafío, Luhmann (2007) argumenta que uno de los principales obstáculos epistemológicos para la formación de una teoría específica de la sociología consistiría en la obtusa tendencia a definir la(s) sociedad(es) como unidad(es) regional(es), territorialmente delimitada(s); de modo que América Latina, por ejemplo, sería una sociedad y Europa otra; Chile una y Argentina otra, dentro de los cuales los mapuches, por ejemplo, serían a su vez otra sociedad distinta. No obstante, si para el padre de la teoría esto se resolvía en términos estrictos de las capacidades metateóricas, en el caso de Chernilo y Mascareño (2005) la respuesta se alcanza en la medida de la globalidad de un patrón histórico-social concreto, que si bien tiene su origen en Europa, se define precisamente por establecer condiciones planetarias: la sociedad mundial y, dentro de ésta, la evolución social de la trayectoria latinoamericana de la modernidad como diferenciación funcional concéntrica ${ }^{6}$.

A lo largo del desarrollo histórico, los tres obstáculos se desplegarían bajo distintos énfasis según el primado de cada cual. Lo constante sería una visión particularista que impide observar lo específico de un contexto -un país o la sociedad latinoamericana- como variación de una unidad que lo trasciende. A juicio de los autores, los pensadores latinoamericanos han tendido a entender lo universal como negación de lo particular y, por tanto, lo distinto como barbarie frente a la civilización -a partir de la segunda mitad del siglo XIX-, como subdesarrollo frente al desarrollo de los centros -a mediados del siglo XX-, o como fuente potencial liberadora de virtudes espirituales frente al utilitarismo de los pueblos sajones arielismo a inicios del siglo XX. Por ello, el obstáculo estructural de la modernidad latinoamericana se pretende superar mediante las características que la diferenciación funcional habría alcanzado en América Latina. Por lo tanto, la modernidad no puede ser identificada al horizonte de la civilización, o el modelo de poderosa federación que encarna el espíritu del utilitarismo en Ariel, sino que -siguiendo la interpretación de las trayectorias de modernidad (Larraín 1997) - en tanto fenómeno global que debe ser especificado, más allá de sus particularidades, en su diversidad de trayectorias regionales. 
Los ejemplos clásicos que acabamos de mencionar aluden a la forma integrada en que funcionan los tres obstáculos epistemológicos en la tradición intelectual. Bajo la semántica del progreso, en el periodo positivista decimonónico, la condición de "versión limitada" -de atraso, de barbariede América Latina derivó en un diagnóstico pesimista sobre el estado vigente de la realidad continental, por consiguiente en la necesidad de transformarla para alcanzar la civilización -identificada con la experiencia de los países europeos y Estados Unidos. Por otra parte, la reacción indentitaria ${ }^{7}$ que encarna Ariel ejemplificaría el otro lado de la forma: América Latina, en virtud del valor de su identidad, señala "el punto de fuga". Esta segunda posición se acerca a lo que Larraín (1997) apunta como parte de una intelectualidad opuesta a la modernidad -a la versión ilustrada, industrial y protestante de los centros- en función de la reivindicación de una matriz cultural "propia".

El punto medular es que los obstáculos dan cuenta de la tendencia a identificar lo universal con base a un contexto concreto, aparentemente ajeno a la realidad social continental, como lo serían las vigencias europeas y norteamericanas de la modernidad; sin poder observar que la trayectoria latinoamericana constituye, a su modo, una articulación con la sociedad mundial -desde luego: moderna- por medio de su proceso de diferenciación funcional. Este paso de un nivel mayor de abstracción coincide con Luhmann (2007: 123) en que las diferencias que hay en el grado de desarrollo en las distintas regiones no deben ser observadas bajo una idea de sociedad regional, sino partiendo de la sociedad mundial y su diferenciación por funciones: "De esta manera puede verse mejor y, sobre todo, explicarse mejor por qué ciertos datos regionales hacen la diferencia y por qué diferencias existentes se acrecientan o disminuyen según la manera en que se encuentran entrelazadas circularmente con las condiciones de la sociedad del mundo”.

Contraria a esta posición, en las últimas décadas, los debates decoloniales en torno a la modernidad plantean nuevas miradas con respecto a la lectura crítica expuesta desde la sociología. Ya no se trataría de los obstáculos para alcanzar una teorización determinada, sino que el obstáculo principal sería precisamente preocuparse por encontrar una salida vía este camino, no sólo porque lo que está en juego es la posibilidad de generar un pensamiento crítico que vuelve a situarnos en la discusión sobre la autenticidad/originalidad de la producción intelectual latinoamericana, sino porque la misma pretensión de universalidad del conocimiento es cuestionada y por lo tanto la reflexión se orienta necesariamente a las condiciones epistemológicas que la fundamentan. Ahora, la consideración crítica hacia la carga de la propia tradición argumenta este punto en torno a una novedosa problematización: que no hemos logrado desprendernos de un estado de tutelaje intelectual impuesto por el eurocentrismo. En este sentido, la decolonialidad conduce a rechazar la pretensión a partir de una crítica a la epistemología moderna que la fundamenta. Este paso tiene como punto de partida una redefinición del fenómeno de la modernidad y el cuestionamiento de sus orígenes espaciales y temporales en torno a la colonialidad $^{8}$-el lugar de América Latina en la sociedad mundial. 


\section{La decolonialidad y el rechazo a la universalidad}

La pregunta inicial que debemos contestar es ¿cómo se posiciona la decolonialidad con respecto a su pasado intelectual del cual busca desprenderse, en lo considerado parte de una genealogía de pensamiento crítico? La respuesta inmediata se encuentra en el texto fundante del grupo Modernidad/Colonialidad, titulado Mundos y conocimientos de otro modo. El programa latinoamericano de investigación de modernidad/colonialidad, publicado en el 2003. Aquí se apela al desprendimiento con lo hasta entonces considerado como "las contribuciones más originales de Latinoamérica al pensamiento crítico del siglo XX” (Escobar 2003: 3), hacia un esfuerzo por construir un pensamiento social/crítico descolonizado. El punto de partida está dado por una redefinición del fenómeno de la modernidad cercano a la tesis del sistema-mundo (Wallerstein 1979) y una especial consideración al tema del eurocentrismo.

Si la modernidad se concibe como resultado y deriva endógena de la experiencia histórica europea -Reforma, Ilustración, Revolución francesa, Revolución industrial-, se asume un esquema de periodización particular como patrón que deviene global producto de factores internos. Desde esta perspectiva de un orden global eurocentrado, la modernidad representa una fase de superación histórica global: la salida de la inmadurez de la humanidad hacia una nueva fase de desarrollo que debe ser alcanzado por todos los pueblos. Esta es una concepción que se habría consolidado en Europa, esencialmente en el siglo XVIII e inicios del XIX ${ }^{9}$, y su interpretación eurocéntrica perduraría hasta nuestros días ${ }^{10}$.

Por otro lado, a partir de la perspectiva del sistema-mundo, la modernidad es concebida en su articulación con el capitalismo y la colonialidad. Se trataría de un fenómeno que comenzó hace cinco siglos con la apertura y control del Atlántico. Al respecto, Dussel (1993: 46) propone:

una segunda visión de la 'Modernidad', en un sentido mundial, [que] consistiría en definir como determinación fundamental del mundo moderno el hecho de ser (sus Estados, ejércitos, economía, filosofía, etc.) ‘centro’ de la Historia Mundial. Es decir, nunca hubo una sociedad mundial, sino hasta 1492 (como fecha de iniciación del despliegue del sistema-mundo).

Anteriormente a esta fecha, los imperios o sistemas culturales coexistían entre sí. Sólo con la apertura del circuito Atlántico y la instauración de la colonialidad del poder, todo el globo se torna el lugar de una sola sociedad, de una sola historia hegemonizada por Europa. El proceso de formación de la modernidad/colonialidad está articulado sobre la base del comercio y las dinámicas de dominación y explotación entre las distintas regiones, su complementación con los patrones de la división internacional del trabajo y la jerarquía étnico-racial -colonialidad del poder. Este hecho es dependiente de la transformación estructural que favorece, por primera vez en la historia, la formación del sistema-mundo. Desde entonces, los contex- 
tos regionales coexistentes, ajenos a la influencia europea, quedan subsumidos a la totalidad integradora de las condiciones dominantes que han sido establecidas por la sociedad mundial.

Uno de los efectos de esta subsunción opera en el nivel del conocimiento y tiene que ver con el desplazamiento y subalternización que lleva a cabo el saber legitimado por el centro hacia las formas culturales de la periferia. La pretensión universal de la razón moderna, al sobreponerse sobre todo tipo de particularidad local, da cuenta del correlato intelectual europeo como actitud colonial del conocimiento:

La superioridad asignada al conocimiento europeo en muchas áreas de la vida fue un aspecto importante de la colonialidad del poder en el sistema-mundo. Los conocimientos subalternos fueron excluidos, omitidos, silenciados e ignorados. Desde la Ilustración, en el siglo XVIII, este silenciamiento fue legitimado sobre la idea de que tales conocimientos representaban una etapa mítica, premoderna y precientífica del conocimiento humano (Castro-Gómez \& Grosfoguel 2007: 20).

Por descolonización epistemológica se entiende entonces un intento que, en base a la redefinición del fenómeno de la modernidad como relación de poder de alcance global que impone condiciones materiales y culturales dominantes -relacionadas, por ejemplo, al dominio de lo epistémico-, busca la gestación de un pensamiento en diálogo con conocimientos de la periferia que han sido despreciadas y/o silenciadas por la superioridad autoasiganda de la cultura europea.

\section{Colonialidad del poder}

El proceso de la colonialidad del poder es constitutivo al proceso de formación de la modernidad/colonialidad -vista como sistema-mundo. Dos cuestiones se imbrican en esta idea, el control sobre el trabajo y la discriminación racial (Quijano 1993) ${ }^{11}$. En este punto, vale remarcar una doble precisión entre modernidad y modernidad/colonialidad:

a) Por modernidad se define el proceso histórico y su correspondiente interpretación eurocentrada que asume las transformaciones de la sociedad mundial como fenómeno protagonizado por Europa; se trata del correlato discursivo de estas transformaciones que identifica la experiencia europea como experiencia global. La modernidad no se comprende desde una región particular, sino un todo integrado bajo ciertas condiciones dominantes -en sistemas de función, o en torno al sistema moderno/colonial capitalista. Sin embargo, su anclaje geo-histórico tiene como efecto desencadenante un orden de relaciones asimétricas: en perspectiva de los centros se comprende como autodirección de la historia y en las regiones periféricas como un horizonte (de civilización o desarrollo) que debe ser alcanzado o rechazado. 
b) Modernidad/colonialidad atiende a lo estrictamente estructural de las transformaciones que dieron paso a la formación del sistemamundo. Se trata de la escala global que alcanza el capitalismo con la colonialidad del poder y la centralización de los centros occidentales. Una determinada formación social que se articuló a escala planetaria en la medida en que Europa subsume progresivamente a las demás regiones desplazándolas a la periferia según sus modos de articulación a las condiciones dominantes.

La modernidad, la colonialidad y el eurocentrismo son fenómenos mutuamente dependientes y constitutivos, donde las diversidades locales -la heterogeneidad histórica, de recursos, de culturas, de subjetividades y conocimiento periféricos- se incorporan a un sistema de coordinación global: "los europeos generaron una nueva perspectiva temporal de la historia y re-ubicaron a los pueblos colonizados, y a sus respectivas historias y culturas, en el pasado de una trayectoria histórica cuya culminación era Europa” (Quijano 1993: 210). Por otro lado, este proceso implica efectos diferenciados según el grado de articulación en que las regiones se integran a las condiciones dominantes; por ejemplo, la colonialidad del poder explica cómo diversas regiones ingresan de manera desigual al patrón capitalista en función de su posición geocultural y en la jerarquía étnico-racial respectiva. En este aspecto, una segunda dimensión derivada opera como colonialidad del saber.

\section{Eurocentrismo y geopolítica del conocimiento}

El eurocentrismo es una consecuencia de la posición hegemónica que alcanza Europa en la sociedad mundial: "Solamente el conocimiento generado por la elite científica y filosófica europea era tenido como conocimiento verdadero, ya que era capaz de hacer abstracción de sus condicionamientos espacio-temporales para ubicarse en una plataforma neutra de observación” (Grosfoguel \& Castro-Gómez Ibíd.). Equivale a la actitud epistemológica de la modernidad que autodecreta una forma de producir conocimiento como la forma. La introducción de los conceptos de Mignolo (2012) de la “diferencia colonial”, y la “corpo” y “ego-política” del conocimiento, permite dilucidar este punto relacionando espacios de enunciación con el desarrollo de modos de pensamiento. La epistemología moderna, caracterizada por desconocer sus condicionamientos contextuales, respondería a un escenario de enunciación propio de la posición hegemónica del centro. Por lo tanto, el cogito habría sido posible gracias a los efectos de configuraciones históricas de poder que posibilitan un escenario de enunciación que puede hablar en nombre de la humanidad entera.

En la terminología de Castro-Gómez (2007), esta actitud se presenta en la hybris del punto cero. La tesis del autor se apoya en el racionalismo cartesiano para clarificar su argumentación puesta en el discurso filosófico que inaugura la modernidad para esclarecer qué tipo de conocimiento será declarado "verdadero" y bajo qué condiciones. En el Discurso del método 
(1952), Descartes funda el saber de la ciencia en la ruptura con el principio de autoridad medieval y sobre cualquier otro tipo de conocimiento. Sólo la ciencia se ocupa de las cosas verdaderas, las que son posibles de concebir de manera clara y distintamente; siendo, lo primeramente indudable para este efecto, el sujeto que piensa, que va más allá de cualquier cultura o localización. Se trata del punto cero cartesiano que reside en la certeza última que provee la razón descorporeizada:

Tanto en el Discurso del Método como en las Meditaciones Metafísicas, Descartes afirma que la certeza del conocimiento sólo es posible en la medida en que se produce una distancia entre el sujeto conocedor y el objeto conocido [...], los sentidos constituyen un obstáculo epistemológico para la certeza del conocimiento y que, por tanto, esa certeza solamente podía obtenerse en la medida en que la ciencia pudiera fundamentarse en un ámbito incontaminado por lo empírico y situado fuera de toda duda (Castro-Gómez 2007: 82).

Este ámbito metaempírico de observación para dirigir la razón y buscar la verdad en las ciencias se resuelve en la incorporeidad del cogito y en una ontología de dualismo sustancial ${ }^{12}$. Desde el cogito, la realidad del conocimiento sólo se revela bajo las ideas claras y distintas que son las propiedades de las cosas observables matemáticamente y que permanecen ocultas a la experiencia directa. El sujeto que se relaciona con el mundo que conoce -res extensa- es un sujeto esencialmente mental -res cogitans. La razón constituye la instancia definitoria del ser humano que no depende de tener un cuerpo. En este racionalismo abstracto se inaugura la pretensión universal del conocimiento de la epistemología, porque al dar fundamento en la capacidad estrictamente mental, el ego cogito y el conocimiento científico puede prescindir de las propiedades corporales de extensión -que significan sentidos, historia, cultura-, pero no así de la propiedad de la razón que lo define.

La solución cartesiana de una razón más allá de cualquier lugar, tiempo y espacio -equivalente a la mirada de Dios-, implica lo que Mignolo (2012) llama el tránsito de la teo-política a la ego-política -contrario a la corpo-política- del conocimiento. El cogito pone al "yo pienso” en el lugar de Dios y reemplaza todos sus atributos como sujeto del conocimiento: Dios no responde a una historia, sexualidad, género, etnicidad, raza, clase, espiritualidad, ni localización epistémica en ninguna relación de poder. En este sentido, Grosfoguel (2007) se refiere al universalismo abstracto del sujeto epistémico sin rostro ni localización espacio-temporal. Noción que ha perdurado como el legado vigente hasta nuestros días del cartesianismo. Es el acto de la epistemología del punto cero que pretende declarar universalmente valido un conocimiento abstracto, vaciado de cuerpo y contenido y, por supuesto, de cualquier tipo de localización en la cartografía del poder mundial. El modelo epistémico de la hybris del punto cero resume la actitud eurocéntrica de la modernidad al "establecer un punto de vista sobre todos los demás puntos de vista, pero sin que de ese punto de vista se puede tener un punto de vista” (Castro-Gómez 2007: 83). Es el privilegio epistémico 
del primer mundo; el supuesto subyacente, siguiendo a Mignolo (2003), de que el conocimiento que no sea producido en los centros, sobre todo aquel que se produce en África, Asia o América Latina no es propiamente conocimiento. Por tanto, sólo una epistemología -fronteriza- que trabaje en el límite de los conocimientos subalternizados por la colonialidad del saber puede aspirar a una descolonización intelectual.

\section{Teoría sociológica y teoría social}

Si la crítica desde la sociología se presenta como una deficiencia teórica, en las propuestas decoloniales la problemática de la universalidad se pone en cuestión, ya que el foco de la reflexión se dirige a la relación eurocentrismo como condición de posibilidad. El argumento central se puede resumir en la hipótesis de que las pretensiones universales de la razón develarían una condición sine qua non con el despliegue de la colonialidad del poder y de la geopolítica del conocimiento. Bien señala Grosfoguel (2007), Descartes piensa su filosofía desde Ámsterdam, precisamente en el periodo en que Holanda se posiciona en tanto centro del sistema-mundo; precedido por siglo y medio del ego conquiro -yo conquisto- ${ }^{13}$ el ego cogito representa "el sujeto cuya localización geopolítica está determinada por su existencia como colonizador/conquistador, es decir, como Ser imperial”.

Por otra parte, el conocimiento declarado "verdadero" solamente puede partir de un sujeto blanco-europeo-masculino-heterosexual (Grosfoguel 2007). El pensamiento occidental tiene como condición de posibilidad no sólo una localización geopolítica imperial/colonial, sino además un racismo epistémico subyacente. De esta manera, la pretensión universal no puede ser otra cosa que un producto eminentemente del eurocentrismo, y éste el correlato de una voluntad de poder actuante en la formación de la modernidad/colonialidad. Para invisibilizar la relación universalidad/poder, la epistemología moderna ${ }^{14}$ se verá obligada a recurrir a instancias de transcendentalismo cada vez más abstractas que fundamenten el acto de pensar escindido de cualquier tipo de localización en tanto acto "plenamente racional”, al mismo tiempo en que la modernidad -la de la primera definición que vimos arriba- se identifica como movimiento mundial adscripto a un único patrón civilizatorio.

Por lo tanto, la respuesta crítica decolonial hacia la carga de la propia tradición intelectual incurre como opción epistemológica, ético-política e historicista. Tres puntos centrales derivan de esta doble consideración:

a) un rechazo a lo que desde la sociología se designa como la deficiencia teórica del pensamiento social latinoamericano, implicando

b) una revitalización de la misma deficiencia, en términos de un cuestionamiento a la pretensión de universalidad a partir de una reformulación del fenómeno de la modernidad y su carácter eurocéntrico; 
c) una descolonización epistemológica como reacción frente al pensamiento occidental -desprendimiento- y su pretensión de universalidad a través de una valorización -apertura- de saberes y epistemes sometidas/subalternizadas/despreciadas por el eurocentrismo del pensamiento occidental ${ }^{15}$.

Llegados a este punto nos interesa introducir una distinción que podría destacar otros relieves en la discusión. Nos referimos a la distinción entre teoría sociológica y teoría social (Chávez 1983). Lo cual nos permite replantear la pregunta por dónde ubicar las pretensiones de universalidad del conocimiento y, asimismo, su puesta en cuestión. Con ello, se pretende dilucidar un punto intermedio entre las dos posturas expuestas: la crítica al pensamiento social latinoamericano en sus obstáculos para elaborar cierto tipo de teorizaciones y la crítica/rechazo al eurocentrismo de la epistemología.

El plano de la teoría sociológica se refiere a la dimensión metateórica, acerca de las capacidades para dar cuenta de un objeto de conocimiento postulado y aprendido como universal. Se trata de lo clásico del conocimiento sociológico, en términos del fundamento universalista a partir de la referencia inmanente de una idea de sociedad que busca trascender las particularidades contextuales. Siguiendo a Chernilo (2011), este desafío debe es aclarado tanto a nivel teórico -la definición de un dominio de conocimiento ontológicamente distinto que emerge con independencia de la psicología individual y de la herencia biológico-cultural común entre los seres humanos-, metodológico -por medio de qué herramientas llegamos a conocer las características de esta realidad sui generis que llamamos sociedady normativo -cómo una determinada teorización deviene en una crítica de la sociedad.

La pretensión universal del conocimiento sociológico, a lo largo de su historia, radica en su capacidad conceptual para construir un objeto de reflexión vinculante a dichos imperativos: la idea de sociedad a través de sus diversas reformulaciones paradigmáticas que determina ciertos universos empíricos y valorizaciones éticas. El desafío se desplaza a la pregunta: ¿qué es la sociedad? o, mejor dicho, ¿en qué consiste la operación constitutiva de lo social? Y se trata de que la respuesta permita un concepto que mantenga la cualidad emergente del objeto definido -la operación constitutiva de lo social como sistema operativamente clausurado de comunicación o trabajo ${ }^{16}$. En otras palabras, ésta no se agotaría en una formación social e histórica concreta -como lo es la diferenciación funcional o el sistemamundo capitalista-, puesto que la universalidad, en primera instancia, no dependería de un contexto histórico concreto ${ }^{17}$, sino estrictamente de la dimensión metateórica del concepto.

Por teoría social, se entiende una caracterización histórica general que se hace de la sociedad en un determinado momento de su evolución. Aquí cabe la pregunta inicial ¿qué es lo que caracteriza como moderna a la sociedad moderna? Interrogante que alude a la historicidad concreta del objeto sociedad. En el primer nivel la sociedad da cuenta de un concepto 
general y abstracto; en el segundo, se trata de cómo ésta se materializa empíricamente en un momento histórico concreto que ciertamente ha conducido a la modernidad.

El que la diferenciación funcional valga como una descripción empírica general del momento presente de la evolución social corresponde a este segundo nivel, pero recordemos: la diferenciación funcional atiende a la globalización histórica de una formación social concreta que alcanza un despliegue global. Aquí se incurre en establecer una relación entre aspiración de universalidad de la teoría y dimensión histórica, pero dicha caracterización no tiene que ver con la vigencia del concepto de sociedad -comunicación- señalado en la primera dimensión, sino directamente con las dinámicas que hacen global un contexto histórico. Modernidad/colonialidad también se está refiriendo a una formación social concreta vista desde el despliegue del capitalismo y la colonialidad del poder. Por lo que también se trata de una distinción histórica relativa a la teoría social, donde la posibilidad de la sociedad mundial está dada por la forma en que todas las regiones del globo quedan articuladas en centros y periferias. Ambas posiciones identifican lo problemática en la teoría social y no en la pregunta por la teoría sociológica.

\section{Consideraciones finales}

La afirmación de Dussel (1993: 48) de que “el eurocentrismo de la modernidad es exactamente haber confundido la universalidad abstracta con la mundialidad concreta hegemonizada por Europa como centro”, pone en cuestión la tensión de las dimensiones teóricas indicadas. La crítica decolonial de rechazo, al igual que la crítica desde la sociología de obstáculo, se basa en el diagnóstico de la teoría social.

La problemática universalidad como aspiración de conocimiento representa una deficiencia teórica en el pensamiento social/sociológico latinoamericano que debe resolverse. Así, se opta por el camino de la adaptación-validación teórica ubicada en el nivel de las caracterizaciones históricas. El problema queda sometido entonces a esclarecer la forma de la diferenciación funcional de la sociedad latinoamericana. De modo que el primer obstáculo epistemológico se superaría con la hipótesis de la diferenciación funcional concéntrica, a diferencia de la policéntrica que corresponde a la experiencia de los centros. Queda planteada una paradoja señalada en el mismo obstáculo: ¿si la sociedad latinoamericana se entiende como el resultado de una evolución distinta de la diferenciación funcional europea, acaso esta diferencia puede convertirse en un criterio de desarrollo que justifica una crítica comparativa acerca de las debilidades del pensamiento social/ sociológico latinoamericano ${ }^{18}$

Para la decolonialidad, la crítica parte desde la solución: salir del eurocentrismo para avanzar hacia una descolonización del conocimiento. Nos encontramos así con que el primer paso es un rechazo a la universali- 
dad como problemática genuina que debe ser resuelta, puesto que la relectura en torno a la modernidad/colonialidad apunta al eurocentrismo epistemológico como un dispositivo homogenizante, geopolítico y racialmente excluyente. No sería muy injusto si desde la óptica decolonial apuntamos que el camino propuesto por Chernilo y Mascareño (2005), en este sentido, es aceptar los términos del eurocentrismo y someterse al tutelaje de su racionalidad.

Ciertamente, con Chernilo (2011: 24), podríamos ofrecer un contraargumento al posible reproche del camino que propone con Mascareño, tomando en cuenta su lectura sobre qué consistiría el desafío mayor:

Compatibilizar una crítica al eurocentrismo que es inmanente al concepto de sociedad moderna [...] pero no bajo condiciones de particularismo o relativismo exacerbado [en lo que incurre la decolonialidad] sino, por el contrario, bajo el alero que provee una creciente reflexión sobre la pretensión universalista de conocimiento de la sociología. Es la idea misma de deslindar los componentes efectivamente universales del proyecto moderno lo que debiera estar a la base del entendimiento de los desarrollos históricos regionales, nacionales y continentales más allá de Europa occidental.

Y más adelante, sobre cómo un proyecto de estas características topa directamente con las capacidades del pensamiento social latinoamericano para dar cuenta de la trayectoria latinoamericana de la modernidad, desnaturalizando la idea de “versión limitada”, asimismo de las concepciones sobre el progreso y la identidad, dice:

Esta reflexión toma como punto de partida un concepto de sociedad moderna que, en el marco del rol de la sociedad como ideal regulativo, no se iguala a ninguna formación histórica específica, y que por tanto asume la variabilidad histórica como un supuesto de base (Chernilo, 2011; 25).

Sin embargo, la respuesta que da Chernilo para superar el eurocentrismo sin tener que rechazar el universalismo deja entrever el mismo camino señalado en coautoría con Mascareño: el eurocentrismo puede ser superado hallando la forma en que se materializa las dimensiones globales de la diferenciación funcional en América Latina. Del mismo modo en que la crítica decolonial incurre en un paso similar al identificar universalidad con el despliegue global de una formación histórica. La interrogante sería entonces, ¿si acaso el rechazo a la universidad de la razón como crítica a la racionalidad eurocéntrica anularía dicha pretensión en la dimensión de la teoría sociológica?

Un ejemplo notable, que nos enseña sobre la forma en que desde Latinoamérica se ha tendido a abordar la pretensión sociológica, de manera similar a los casos aquí tratados, lo constituye la teoría de la dependencia. 
En base a los antecedentes teóricos cepalianos, los debates en torno al desarrollo y la tesis de Prebisch (1949), Marini (2008) intentó describir el carácter del capitalismo periférico y del desarrollo dependiente de América Latina acuñando la distinción de plusvalía relativa y absoluta. Con estos conceptos, Marini trataba de aterrizar la forma del capitalismo en la sociedad latinoamericana tomando en cuenta las dinámicas de competencia entre capitales globales y nacionales, y de paso avanzaba en la formulación de una teoría marxista de la dependencia. Al tomar en cuenta la dinámica global de acumulación según la densidad del grado de desarrollo de las fuerzas productivas de las distintas economías, Marini trataba de encontrar lo universal en el nivel de la teoría social: el capitalismo.

Según Grosfoguel (2007), el viraje materialista del idealismo filosófico y de la dialéctica hegeliana en Marx, encuentra su pretensión de universalidad en la perspectiva de la lucha de clases y en los modos de producción. El eurocentrismo epistémico de Marx se reflejaría en la invisibilización de su espacio de enunciación que en nombre del proletariado europeo de los países desarrollados pretende tener como referencia a la humanidad completa. "Lo que Marx mantiene en común con la tradición filosófica occidental es que su universalismo, a pesar de que surge desde una locación particular, en este caso el proletariado, no problematiza el hecho de que dicho sujeto sea europeo, masculino, heterosexual, blanco, judeo-cristiano" (Grosfoguel 2007: 69). Volvemos al mismo punto recién formulado: universalidad se vuelve a identificar con un patrón histórico social.

Teoría sociológica y social tratan de dos dimensiones teóricas con sus respectivos énfasis de universalidad: lo estrictamente conceptual y lo estrictamente histórico de la sociedad y de la modernidad. El dónde se ubique el énfasis tiene distintas consecuencias para la discusión y la forma en que nos posicionamos frente a nuestro objeto de reflexión: la sociedad latinoamericana. Si la pretensión de universalidad depende de la vigencia de una determinada formación social a escala global, entonces de lo que se trata es de esclarecer el proceso de diferenciación funcional en América Latina y, con esto, "salvar" las deficiencias teóricas del pensamiento social latinoamericano -además debemos suponer que este ejercicio de contextualización no sería codependiente del desarrollo histórico europeo de la ciencia de la sociedad y sus respectivas condiciones epistemológicas ${ }^{19}$. El concepto de sociedad debe mantener su cualidad emergente y no ser identificada a ningún contexto histórico concreto. El valor de la distinción teoría social/sociológica debe habilitarnos para remirar la discusión y poder replantearnos las coordenadas de un tópico clásico en nuestra tradición intelectual, sin antes vernos obligados a rehuir de la conversación. 


\section{Notas}

${ }^{1}$ Este ensayo tiene como antecedente directo la investigación Postcolonialismo y el problema de la identidad en el pensamiento latinoamericano, presentada por los autores el año 2010 como tesis para optar al grado de antropólogo en la Universidad Austral de Chile. Se trabajó en este proyecto bajo la coordinación del profesor Miguel Chávez Albarrán (Universidad de la Frontera), del cual rescatamos gran parte de las ideas que inspiran las hipótesis recorridas aquí.

${ }^{2}$ A juicio de Germani (2010: 161), el pensamiento sociológico latinoamericano se encuentra en una crisis intelectual que describe una situación opuesta a la realidad anglosajona: “El 'ensayismo', el culto de la palabra, la falta de rigor son los rasgos más comunes en la producción sociológica del continente. Lejos del 'perfeccionismo' y el 'formalismo metodológico' yanquis, escasea o falta la noción misma de método científico aplicado al estudio de la realidad social”. Sobre la discusión de la sociología latinoamericana como ciencia teórica y empírica, véase el estudio de Sautu et al (2010).

${ }^{3}$ La problemática histórica de la dependencia ha comprendido una preocupación permanente en el pensamiento social latinoamericano. De ahí que una primera aclaración necesaria sugerida por Beigel (2009) sea distinguir el concepto de dependencia vinculado a la constatación de una condición histórica y estructural cambiante de América Latina, del depedentismo. Refiriéndose, con este último, a la reflexión teórico-crítica sobre la condición periférica de América Latina entre las décadas de 1960 y 1970 periodo en que destacan nombres como Raúl Prebisch, Celso Furtado, Osvaldo Sunkel, Aníbal Pinto, Theotonio Dos Santos, Bania Bambirra, Ruy Mauro Marini, Roberto Pizarro, Orlando Caputo, Fernando H. Cardoso, Enzo Faletto, Franz Hinkelammert y Agustín Cueva; e instituciones como CEPAL, CESO, ILPES, CEREN y FLACSO.

${ }^{4}$ De acuerdo a la literatura existente, hace aproximadamente dos décadas atrás que el programa del grupo Modernidad/Colonialidad se inserta como perspectiva del debate latinoamericano. La emergencia de este grupo respondió al interés por un reordenamiento global del derrotero histórico, relacionando la generación capital de la modernidad y la colonialidad, empresa cuyos rastros se encuentran presentes en diversas acciones de dominio en la actualidad. Una genealogía del programa encuentra registro en la trastienda de la tradición latinoamericana: dependentismo, teología de la liberación, en los aportes de Darcy Ribeiro, Rodolfo Kusch, Orlando Fals Borda y Enrique Dussel. De la misma manera, fuentes que han vertido fuerzas orientadoras deambulan en torno a la teoría feminista chicana, la teoría poscolonial, la filosofía africana, los estudios culturales, los estudios subalternos asiáticos y el grupo de estudios subalternos latinoamericanos.

${ }^{5}$ Los autores puntualizan la tesis de Luhmann (2007) para dar cuenta de la crítica del sociólogo alemán al estado de la producción teórica de la sociología contemporánea mediante el concepto de “obstáculo epistemológico" usado por Bachelard (2010). Para Bachelard (2010: 8), la abstracción teórica es el derrotero fundamental mediante el cual el espíritu científico conduce el camino de su desarrollo hacia construcciones más metafóricas que reales: "En efecto, si se reflexiona sobre la evolución del espíritu científico, se discierne de inmediato un impulso que va de lo geométrico, más o menos visual, a la completa abstracción”. Evidencia de esto es la revolución del conocimiento que irrumpió con la física cuántica en la época del filósofo francés. 


\begin{abstract}
${ }^{6}$ Para una mayor discusión sobre este tema, véase Mascareño (2012) donde el autor esclarece su afirmación sobre las estructuras modernas de la sociedad latinoamericana como diferenciación funcional concéntrica. Lo que se caracteriza por un centro regulador de organización social ejercido por un sistema dominante que dificulta el despliegue autónomo de los demás sistemas.
\end{abstract}

${ }^{7}$ Sobre la reacción indentitaria del pensamiento latinoamericano a inicios del siglo XX, véase el trabajo de Devés (2000).

${ }^{8}$ En esta distinción seguimos a Mignolo (2007a), para quien el “colonialismo” se refiere a periodos históricos específicos y lugares de dominio imperial -español, holandés, británico y, desde principios del siglo XX, estadounidense-; la "colonialidad”, en cambio, denota la estructura lógica del poder que subyace al control transitorio de la economía y política del Atlántico por parte de los centros del sistema-mundo: España, Holanda, Gran Bretaña y Estados Unidos.

${ }^{9}$ Hegel (2005), por ejemplo, en la primera gran sistematización de la historia universal, declara que la dirección del espíritu del mundo va de Oriente a Occidente, y Europa, autoproclamada vigente heredera de toda la humanidad pasada, es el centro y el fin de la historia. Tal como el sol nace en Oriente, el espíritu comienza su marcha en China, pasa por India, Persia y Egipto, para luego entrar a Occidente por Grecia, después Roma y el Mediterráneo, hasta encontrar su perfectibilidad en el mundo europeo germánico. Y si la historia universal es el curso de la evolución del espíritu que no había atravesado por América, sino hasta su contacto con Europa, entonces ¿qué es lo que sucede con el mundo existente antes de la llegada de los conquistadores? La respuesta es que cuando el soplo de la civilización europea ingresa a estas tierras, hace perecer rápidamente la cultura que habitaba, por su debilidad e inferioridad espiritual y física, la de los indios y la naturaleza; comenta: "Estos pueblos de débil cultura perecen cuando entran en contacto con pueblos de cultura superior y más intensa” (Hegel 2005: 267).

${ }^{10}$ Aquí Dussel (1993: 45) se refiere a que el tiempo y el espacio de la modernidad vista así es lo que interpreta Hegel, y comenta Habermas -y constituye una premisa unánimemente aceptada por toda la tradición europea actual. En otro texto del mismo autor (Dussel 1998), se describe la obra de Habermas como un universalismo racionalista abstracto que confunde universalidad con eurocentrismo y desarrollismo modernizador.

${ }^{11}$ La colonialidad se funda en la clasificación étnico-racial -blancos, negros, indios, amarillos y negros- de la población y sus correspondientes coordenadas geoculturales -Europa, América, Oriente y África. Comenta Quijano (2007) que con América (Latina) el capitalismo se hace mundial y eurocentrado, articulando colonialidad y economía-mundo hegemonizado por el centro europeo. En efecto, se habla de cómo el patrón global de poder establece relaciones sociales de dominación y explotación en torno al control del trabajo y sus productos, legitimándose sobre la base de la relación entre raza y trabajo; además, esta relación se justifica ahistóricamente, es decir, con anterioridad a las estructuras sociales que la sostienen. La esclavitud tiene su justificación en Hegel (2005: 268) porque las debilidades del indio americano "han sido la causa de que se hayan llevado a América negros, para los trabajos duros”. A esto se refiere Quijano (1993) en la forma en qué la distinción de raza se asocia y naturaliza en una relación de -poder- dominación y explotación impuesta que, en el caso del control del trabajo, se hace manifiesta bajo la relación capital-salario, la cual sólo se aplica a los 
blancos, mientras que las razas "inferiores" -indios y negros- les corresponde servidumbre y esclavitud.

${ }^{12}$ Dualismo sustancial quiere decir que existen propiedades -sustancias- ontológicamente opuestas, y a cada sustancia le corresponde un tipo de propiedad específica. Para esto, Descartes desarrolla un planteamiento que se funda en la distinción de tres sustancias plenamente distinguibles: res cogitans -sustancia pensante-, res extensa -sustancia con la propiedad de la extensión material- y res infinita -Dios. Descartes señala entonces la existencia de objetos puramente mentales y objetos puramente físicomateriales que corresponden a la realidad cognoscible.

${ }^{13}$ Dussel (2008: 51) nos habla sobre la constitución de la subjetividad moderna que se remonta al acto de afirmación violenta del Yo conquistador sobre el Otro -indioconquistado/violentado en su cultura y cuerpo. La voluntad de poder del ego conquiro representa, en ese sentido, la protohistoria del proceso de la formación del ego cogito: “El ‘yo colonizo’ al Otro, a la mujer, al varón vencido, en una erótica alienante, en una económica capitalista mercantil, sigue el rumbo del 'yo conquisto' hacia el 'ego cogito’ moderno”.

${ }^{14}$ Grosfoguel (2007: 65) se refiere a dos tipos de recursos de abstracción en los que incurre la epistemología moderna: "primero, en el sentido del enunciado, de un conocimiento que se abstrae de toda determinación espacio temporal y pretende ser eterno; y segundo, en el sentido epistémico de un sujeto de enunciación que es abstraído, vaciado de cuerpo y contenido, y de su localización en la cartografía de poder mundial, desde donde produce conocimientos, para así proponer un sujeto que produce conocimientos con pretensiones de verdad, como diseño global, universal para todos en el mundo". Nosotros partimos del segundo tipo de universalismo abstracto que supone el legado del cartesianismo como continuidad epistémica inherente al estatus del pensamiento occidental.

${ }^{15}$ Desprendimiento y apertura son los dos momentos que señala Mignolo (2007b) para avanzar hacia un pensamiento crítico descolonizado.

${ }^{16}$ En el corpus marxista, la teoría sociológica se relaciona a la categoría de trabajo en un sentido vitalista y antropológico de cultura: el trabajo consiste en la acción del ser humano para transformar la materia en tanto materia de trabajo -cultivar la naturaleza, lo dado- en pos de crear sus propios medios de vida, y asimismo para realizar un proceso de evolución sociocultural acumulativa que lo va transformando también a éste como sujeto de trabajo.

${ }^{17}$ Chernilo (2011) aclara esto en los fundamentos filosóficos que tienen como referencia la idea de ideal regulativo en Kant. El nivel de abstracción que implica la sociedad en tanto ideal regulativo no permite que ésta sea fijada en una formación histórica o geográfica específica.

${ }^{18}$ Un caso sugerente lo podemos encontrar en el examen y la crítica que Mascareño (2003) realiza a la sociología chilena de la dictadura -principalmente con base en los trabajos de Manuel Antonio Garretón y Tomás Moulian-, apuntando al compromiso ético y normativo que asumen los análisis de los sociólogos. A su juicio, esto ha dificultado una interpretación adecuada del proceso chileno, condenando la sociología a adoptar posiciones ideológicas en favor de uno u otro proyecto político de sociedad. 
"Los sociólogos -dice Mascareño (2003: 141)- no han hecho más que querer transformar a Chile; de lo que se trata ahora es de interpretarlo". Sin duda podemos suponer aquí una relación con el tercer obstáculo epistemológico señalado, el de la falta de autonomía, y de este modo aducir a los obstáculos impuestos a la lógica autorreferencial del sistema ciencia. En una diferenciación funcional policéntrica los sistemas operan descentradamente de modo autónomo, ¿no se estaría acaso suponiendo aquello como un criterio ideal de ciencia para la sociología?

${ }^{19}$ A esto nos referimos cuando en principio señalamos que la lectura de Chernilo y Mascareño conduce a una descaracterización de la tradición al anteponer una tipificación del conocimiento sociológico que permite una crítica comparativa en referencia a un canon de conocimiento desarrollado en otros contextos. 


\section{Bibliografía}

Bachelard, Gastón (2010), La formación del espíritu científico. Contribución a un psicoanálisis del conocimiento objetivo, Siglo Veintiuno Editores, Buenos Aires.

Beigel, Fernanda (2009), Autonomía y dependencia académica. Universidad e investigación científica en un circuito periférico: Chile y Argentina (1950-1980), Editorial Biblios, Buenos Aires.

Castro-Gómez, Santiago (2007), “Decolonizar la universidad. La hybris del punto cero y el diálogo de saberes”, en Castro-Gómez, S. (comp.), El giro decolonial. Reflexiones para una diversidad epistémica más allá del capitalismo global, Siglo del Hombre Editores, Bogotá, pp. 79-91.

Castro-Gómez, Santiago y Grosfoguel, Ramón (2007), “Giro decolonial, teoría crítica y pensamiento heterárquico”, en Castro-Gómez, S. (comp.), El giro decolonial. Reflexiones para una diversidad epistémica más allá del capitalismo global, Siglo del Hombre Editores, Bogotá, pp. 9-23.

Chávez, Miguel (1983), La semántica de la identidad en América Latina como generadora de discursos científicos, literarios y de transformación política, Coloquios de investigación Prof. Dr. A. Stoll, Universidad de Bielefeld.

Chernilo, Daniel y Mascareño, Aldo (2005), “Universalismos, particularismos y sociedad mundial: obstáculos y perspectivas de la sociología en América Latina”, en Persona y Sociedad, Universidad Alberto Hurtado, Vol. 19, pp.17-45.

Chernilo, Daniel (2011), La pretensión universalista de la teoría social, LOM ediciones, Santiago de Chile.

Descartes, René (1952), Discurso del método y meditaciones metafísicas, Espasa-Calpe, Buenos Aires.

Devés, Eduardo (2000), Del Ariel de Rodó a la CEPAL (1900-1950). El pensamiento latinoamericano en el siglo XX, entre la modernidad y la identidad, Biblios, Santiago de Chile.

Dussel, Enrique (1993), “Europa, modernidad y eurocentrismo”, en Lander, E. (comp.), La colonialidad del saber: eurocentrismo y ciencias sociales. Perspectivas latinoamericanas, Consejo latinoamericano de Ciencias Sociales (CLACSO), Buenos Aires, pp. 41-53.

-Idem (2008), El encubrimiento del Otro. Hacia el origen del "Mito de la modernidad”, Biblioteca Indígena, La Paz.

Escobar, Arturo (2003), “Mundos y conocimientos de otro modo. El pro- 
grama latinoamericano de investigación de modernidad/colonialidad”, en Tabula Rasa, UCMC, Vol. 1, pp.51-86.

Gaos, José (1993), “El pensamiento hispanoamericano. Antología del pensamiento de lengua española en la edad contemporánea”, en Obras Completas. Tomo V, Universidad Nacional Autónoma de México (UNAM), México D.F., pp. 23-62.

Germani, Gino (2010), La sociedad en cuestión. Consejo latinoamericano de Ciencias Sociales (CLACSO), Buenos Aires.

Grosfoguel, Ramón (2007), “Decolonizando los universalismos occidentales: el pluri-versalismo transmoderno decolonial desde Aimé Césaire hasta los zapatistas”, en Castro-Gómez, S. (comp.), El giro decolonial. Reflexiones para una diversidad epistémica más allá del capitalismo global, Siglo del Hombre Editores, Bogotá, pp. 63-77.

Hegel, Georg W. F (2005), Lecciones sobre la Filosofía de la Historia Universal, Tecnos, Madrid.

Larraín, Jorge (1997), “La trayectoria latinoamericana a la modernidad”, en Revista de Estudios Públicos, Centro de Estudios Públicos (CEP), Vol. 66, pp. 313-333.

Luhman, Niklas (2007), La sociedad de la sociedad, Universidad Iberoamericana, Herder, México D.F.

Marini, Ruy Mauro (2008), “Dialéctica de la dependencia”, en Marini, Ruy Mauro, América Latina, dependencia y globalización. Fundamentos Conceptuales, Consejo latinoamericano de Ciencias Sociales (CLACSO), Buenos Aires, pp. 107-149.

Mascareño, Aldo (2003), “Sociología del golpe”, en Persona y Sociedad, Universidad Alberto Hurtado, Vol. 17, pp. 117-142.

-Idem (2012), “América Latina en la sociedad mundial”, en Caba, S. \& García, G. (ed.), Observaciones latinoamericanas: perspectivas sobre pensamiento social, Ediciones Universitarias de Valparaíso, Pontificia Universidad Católica de Valparaíso, pp. 95-112.

Mignolo, Walter (2003), “Las geopolíticas del conocimiento y colonialidad del poder. Entrevista a Walter Mignolo”, en Polis, Universidad Bolivariana, N¹, online: http://www.redalyc.org/articulo.oa?id=30500409.

-Idem (2007a), La idea de América Latina: la Herida Colonial y la Opción Decolonial, Gedisa, Barcelona.

-Idem (2007b) "El pensamiento decolonial: desprendimiento y apertura. Un manifiesto”, en Castro-Gómez, S. (comp.), El giro decolonial. Reflexio- 
nes para una diversidad epistémica más allá del capitalismo global, Siglo del Hombre Editores, Bogotá, pp. 25-45.

-Idem (2012), “Desobedencia Epistémica, pensamiento independiente y libertad de-colonial”, en Caba, S. \& García, G. (ed.), Observaciones latinoamericanas: perspectivas sobre pensamiento social, Ediciones Universitarias de Valparaíso, Pontificia Universidad Católica de Valparaíso, pp. 7193.

Prebisch, Raúl (1949), “El desarrollo económico de la América Latina y algunos de sus principales problemas”, CEPAL, Santiago de Chile.

Quijano, Aníbal (1993), “Colonialidad del poder, eurocentrismo y América Latina”, en Lander, E. (comp.), La colonialidad del saber: eurocentrismo y ciencias sociales. Perspectivas latinoamericanas, Consejo latinoamericano de Ciencias Sociales (CLACSO), Buenos Aires, pp. 201-246.

-Idem (2007), “Colonialidad del poder y clasificación social”, en CastroGómez, S. (comp.), El giro decolonial. Reflexiones para una diversidad epistémica más allá del capitalismo global, Siglo del Hombre Editores, Bogotá, pp. 93-126.

Sautu, Ruth; Fraga, Cecilia; Najmias, Carolina y Plotno, Gabriela (2010), “La Sociología como Ciencia Teórica y Empírica ”, en C. Mera y J. Rebón (coord.), Gino Germani. La sociedad en cuestión. Antología comentada, Consejo Latinoamericano de Ciencias Sociales (CLACSO), Buenos Aires, pp. 316-324.

Wallerstein, Immanuel (1979), El moderno sistema mundial. La agricultura capitalista y los orígenes de la economía-mundo europea en el siglo XVI, Siglo XXI Editores, Madrid.

Recibido: 15.05.2014

Aprobado: 15.07.2014 